\title{
An exploratory study of informed engineering design behaviors associated with scientific explanations
}

\author{
Şenay Purzer ${ }^{1 *}$, Molly Hathaway Goldstein ${ }^{2}$, Robin S Adams², Charles Xie ${ }^{3}$ and Saeid Nourian ${ }^{3}$
}

\begin{abstract}
Background: Design and science inquiry are intertwined during engineering practice. In this study, we examined the relationship between design behaviors and scientific explanations. Data on student design processes were collected as students engaged in a project on designing energy-efficient buildings on a blank square city block surrounded by existing buildings using a computer-aided design program, Energy3D, with built-in solar energy simulation capabilities. We used criterion sampling to select two highly reflective students among 63 high school students.

Results: The main data sources were design replays (automatic playback of student design sequences within the CAD software) and electronic notes taken by the students. We identified evidence of informed design such as problem framing, idea fluency, and balancing benefits and trade-offs. Opportunities for meaningful science learning through engineering design occurred when students attempted to balance design benefits and trade-offs.

Conclusions: The results suggest that design projects used in classrooms should emphasize trade-off analysis and include time and resources for supporting trade-off decisions through experimentation and reflection. Future research should explore ways to visualize patterns of design behavior based on large samples of students.
\end{abstract}

Keywords: Computer-aided design; Engineering design; Informed design; Scientific inquiry; Trade-offs

\section{Background}

Engineering and technological design has been considered to be a component of K-12 education curricula and standards in a number of countries since the 1970s. Many industrialized countries such as Australia, Great Britain, New Zealand, and the US have implemented reforms for engineering education in K-12 schools to promote technological literacy as well as competencies to create and evaluate design solutions (Cajas 2001; Lachapelle and Cunningham 2014). While engineering design has been a part of the National Science Education Standards in the US (National Research Council 1996), it has gained a new sense of importance worldwide with the increased number of studies examining engineering in association with science learning, twenty-first century skill development, and academic motivation (Brophy et al. 2008; Penner et al. 1997; Sadler et al. 2000; Purzer

\footnotetext{
* Correspondence: spurzer@purdue.edu

${ }^{1}$ School of Engineering Education, Purdue University, Wang Hall 4545, 516

Northwestern Avenue, West Lafayette, IN 47906, USA

Full list of author information is available at the end of the article
}

et al. 2014) and with the publication of a number of reports such as A Framework for K-12 Science Education (National Research Council 2012), the Next Generation Science Standards (Achieve 2013), and STEM Integration in K-12 Education (National Academy of Engineering and National Research Council 2014).

\section{Scientific inquiry vs. engineering design}

Given that engineering is a relatively new subject as compared to science for many educators, curriculum developers, and policy makers, there are many attempts to understand features of scientific inquiry and engineering design and how they might relate or interact with each other (Lewis 2006; National Research Council 2012; Schunn et al. 2012). Lewis (2006) provides a brief history on the push for inquiry in educational standards and identifies key differences and similarities between inquiry and design. He notes that inquiry was first viewed as an intellectual process - the attitudes and activities associated with discovery (Bruner 1961). Over time, definitions of inquiry focused on the intellectual processes peculiar 
to particular aspects of science that were crucial to understanding the nature of science. As such, scientific inquiry became to be understood as more than a technique (i.e., a process or inquisitive stance) but as the content and practices of science (i.e., the role of scientific theory in generating new lines of investigation and how science is done). Scientific inquiry represents the diverse ways in which scientists study the natural world and develop explanations based on the evidence derived from research (National Research Council 1996, p. 23). While scientific inquiry involves observations, posing questions, and examining various sources of information to see what is already known, there is no single scientific method (Penner et al. 1997), and while scientific investigations may share a common set of deductive or inductive reasoning activities, there is 'no fixed sequence of steps that all scientific investigations follow' (National Research Council 1996, p. 3). Instead, inquiry is characterized as a fluid process in which the outcomes are not absolute, but rather tentative.

Similar to scientific inquiry, design is understood to be a complex cognitive activity (Cross 2001; Lawson and Dorst 2009) where there is no one generalized design method (Dubberly 2004) although variations of methods share many elements such as posing, generating, evaluating, and choosing solutions (Lawson and Dorst 2009). Designers tackle and resolve ill-defined or wicked problems in which solutions are neither right nor wrong but rather sufficient (Cross 2006; Goel and Pirolli 1992). This uncertainty requires that designers construct or frame problems, which involves taking into account the problem context and the needs of diverse stakeholders. This occurs through identifying constraints or boundaries on the space in which the designer searches for a solution. Constraints cover a large and often under-determined space from objective parameters (governed by natural or mathematical principles) to subjective values (Goel and Pirolli 1992; Jonassen 2000). As such, designers need to consider trade-offs to select among a set of plausible solutions and may need to revisit early problem formulations or backtrack on design decisions as needed.

Since design problems are often not amenable to exhaustive analysis, the designer uses abductive reasoning to impose conjectures to manage ambiguity and make solutions possible (Dorst 2011; Kolko 2010). They also rely on other cognitive reasoning tools such as analogical reasoning to search for solutions and manage ambiguity (Ball and Christensen 2009; Paletz et al. 2013; Daugherty and Mentzer 2008), visual thinking to amplify the inventive uses of mental imagery (Fish and Scrivener 1990; Goldschmidt 1991; Goldschmidt and Smolkov 2006), and representational thinking to translate abstract requirements into concrete ideas and communicate these ideas to others (Bucciarelli 1996; Cross 2006). Overall, the design process may be characterized as a goaldirected and iterative activity where the mode of problem solving is described as solution-focused (as compared to problem-focused) since a designer learns about the problem through proposing solutions and synthesizing ideas.

As Lewis (2006) describes, notable divergences between engineering design and scientific inquiry include purpose (starting points that emphasize pure versus applied dimensions), the role of constraints (constraints in design are intrinsically woven into design reasoning), the role of trade-offs (science has no parallel to this form of reasoning), and the role of context (design problems are shaped by context whereas science problems seek to transcend context). Two central ways design converges with Scientific inquiry include (a) reasoning processes such as analogical reasoning as navigational devices to bridge the gap between problem and solution and (b) uncertainty as a starting condition that demands expenditure of cognitive resources in the form of search strategies, mental models and visual representations to rehearse and communicate thought, and decision-making via testing and evaluation (Lewis 2006). As stated earlier, both design and inquiry are often referred to as procedures, although no generic procedure exists, and are taught as content in their own right, although they must draw upon a base of knowledge to formulate and solve problems.

Another key point of commonality between engineering design and scientific inquiry is that both emphasize learning by doing. For example, a key performance dimension of design is learning while designing (Crismond and Adams 2012). This includes learning by doing and reflecting, from brainstorming and prototyping, through iteration and feedback from failure, by noticing and troubleshooting, as well as drawing and dialoging with ideas, materials, and people (Adams et al. 2003; Crismond and Adams 2012; Lawson and Dorst 2009; Schön 1993). Similarly, scientific inquiry is characterized as a process of transformative learning that allows expression of both teacher and student voices (Lewis 2006).

While much has been written about comparing design and scientific inquiry, there are limited studies focusing on how K-12 students engage in engineering design and scientific inquiry simultaneously while solving complex and ill-defined problems (Svihla and Petrosino 2008; National Research Council 2009). In this study, we used a computer-aided design software that captured student design activities allowing us access to fine-grained data on students' explanations and actions. More specifically, we asked:

How are secondary school students' design behaviors associated with scientific explanations in informing design decisions? 


\section{Conceptual framework}

Engineering and science manifest and interact to support learning

Learning one (e.g., engineering) through the other (e.g., science) represents an underlying philosophy integrating scientific inquiry and design in K-12 education. Previous research suggests that engineering design is an effective approach to supporting science learning (Apedoe et al. 2008; Hmelo et al. 2000; Kolodner 2002; Kolodner et al. 2003; Doppelt et al. 2008; Schnittka and Bell 2011). Well-documented and effective approaches for which design provides a vehicle for learning science include Learning By Design (LBD) (Kolodner 2002), Model Eliciting Activities (MEA) (Zubrowski 2002), and Knowledge and Skill Builders (Burghardt and Hacker 2004). As an example, the LBD model of constructing and testing real devices provides students with opportunities to test their conceptions and discover the holes in their own knowledge as well as predict the performance of their designs (Kolodner 2002).

Parallel to accounts of design approaches to enhance science learning are those that use science as a vehicle for prompting design. For example, Lewis (2006) describes two activities that ask students to develop design ideas by applying science concepts they learned previously. The first activity by Snetsinger et al. (1999) involves application of electrical and mechanical energy concepts to the design of wind turbines. The second activity by Subramanian (1999) applies thermal expansion principles into the design of bimetallic household products. Despite these examples, there are concerns about the so-called 'design-science gap' (Vattam and Kolodner 2008). A challenge is that such learning is not easily amenable to traditional assessment methods. In classroom practice, critical aspects of science learning tend to be set aside (Apedoe and Schunn 2013) as students focus on aesthetic features or on building and construction as opposed to experimentation, analysis, and justification of design decisions.

Using a conceptual framework that characterizes the interaction between scientific inquiry and design, this study offers an emergent theory of how secondary students learn and apply science concepts through engineering design. The study also offers tools for understanding how engineering and science manifest and interact and the kinds of learning associated with this interaction. As shown in Figure 1, this framework is situated in a shared space of convergence - learning while designing. This space includes learning science through design (where design is the vehicle for learning science), learning design through science (where science serves as vehicle for prompting a design task), and learning design. For this study, learning science focuses on specific concepts that are relevant to the design task. Both learning science and learning design goals

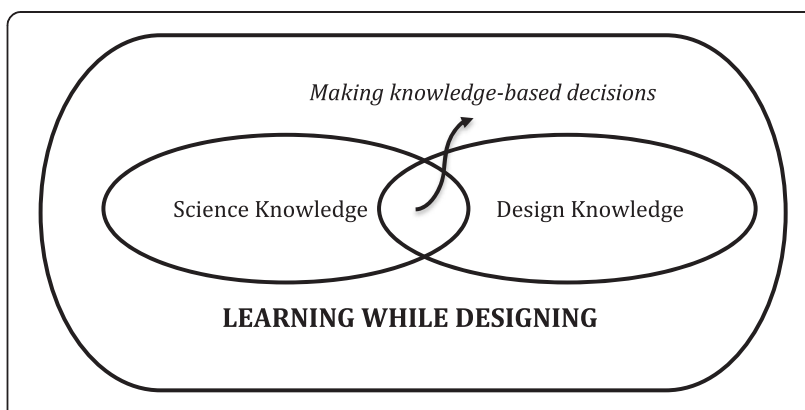

Figure 1 Science and design knowledge informing design decisions.

are essential and in alignment with the NGSS (Achieve 2013).

The intersection of science and design knowledge marks the nature of the interaction between science inquiry and design, making and explaining knowledgebased decisions. Crismond and Adams (2012) describe this as using knowledge of physical laws, how things work, methods of construction, everyday knowledge, application of known cases, and knowledge gained from design revisions and experiments. The framing illustrates the ways science inquiry and design occur concurrently feeding one another. For example, simulation data collected through experimentation can inform the design of specific features. Similarly, the design of multiple prototypes with comparable features can guide scientific inquiry with the goal of evaluating the performance of these alternatives. Together, these activities guide the explanation of relationships among design criteria as well as help inform decisions about making trade-offs among these criteria.

\section{Informed design behaviors}

To qualitatively characterize patterns of student design behaviors, we used Crismond and Adams (2012) Informed Design Learning and Teaching Matrix. The design of this matrix was based on a meta-literature review of more than 50 studies and synthesized key performance dimensions of informed designing and behaviors that distinguish novice and expert designers. Our goal was to explore how these behaviors manifest at the interactions between science and engineering. One of these key performance dimensions is 'using design strategies effectively'. This is defined as knowing when and how to use a range of design practices and strategies, and being open to altering a design approach or decision to accommodate new information and time constraints. These key performance dimensions were translated into nine observable design strategies that were further translated into nine 'contrasting set' statements that could act as a guide for noticing how beginning vs. informed designers do the selected strategies. 
As shown in Table 1, the matrix describes a two-step learning trajectory from 'beginning designer' (that depicts assumptions about prior knowledge and skills of learners as they enter a learning progression) to 'informed designer' (that depicts what learners are expected to know and do by the end of the progression). Here, an informed designer is one whose level of experience includes some formal training in design, and level of competence lies somewhere between that of the novice and expert designer. Collectively, the nine statements represent key elements of design learning that make up effective practice, and each statement describes the signs of beginning designers' less effective design approaches as compared to how informed designers would more effectively perform the same strategy. For example, for the pattern of ignore vs. balance benefits and trade-offs, beginning designers are prone to ignore complexity and trade-offs and make design decisions without weighing all options or attend only to pros of favored ideas or cons of lesser approaches. In contrast, informed designers use words and graphics to display and weigh both benefits and trade-offs before selecting a solution. For the pattern, haphazard or linear vs. managed and iterative designing, beginners design in haphazard ways or do design steps once and in a linear manner. Informed designers do design in a managed way, improving on ideas iteratively through feedback and using strategies multiple times as needed, in any order.

\section{Methods}

\section{Research participants and classroom context}

This exploratory study was conducted at a large public high school located in the Northeast United States. Sixty-three students were enrolled in the engineering track during the spring 2013 semester in five courses that comprised the engineering track. Our intent was to target the students with the richest reflective notes from all students in the sample. We reviewed notes from students who completed at least two unique designs. In reviewing each student's designs, we looked at richness of reflection notes over their three designs. These reflective

Table 1 Informed design patterns (Crismond and Adams 2012)

\begin{tabular}{|c|c|}
\hline $\begin{array}{l}\text { Beginning vs. informed design } \\
\text { patterns }\end{array}$ & Description \\
\hline $\begin{array}{l}\text { Pattern A. } \\
\text { Problem solving vs. problem framing }\end{array}$ & $\begin{array}{l}\text { Beginning designers feel that understanding the design task is straightforward, a matter of comprehending } \\
\text { the challenge as a well-structured problem, which they prematurely and immediately attempt to solve. } \\
\text { Informed designers seek initially to explore and comprehend the challenge as the best they can, delaying } \\
\text { decisions to frame the problem effectively. }\end{array}$ \\
\hline $\begin{array}{l}\text { Pattern B. } \\
\text { Skipping vs. doing research }\end{array}$ & $\begin{array}{l}\text { Beginning designers skip doing research in favor of generating solutions immediately. Informed designers do } \\
\text { research to build knowledge broadly about the problem and potential solutions. }\end{array}$ \\
\hline $\begin{array}{l}\text { Pattern C. } \\
\text { Idea scarcity vs. idea fluency }\end{array}$ & $\begin{array}{l}\text { Beginning designers can start a design project with very few or even just one idea, which they may not want } \\
\text { to discard, add to, or revise. Informed designers want to design with an abundance of ideas and practice idea } \\
\text { fluency to explore the design space and initially seek to avoid favoring any single solution. }\end{array}$ \\
\hline $\begin{array}{l}\text { Pattern D. } \\
\text { Surface vs. deep drawing and } \\
\text { modeling }\end{array}$ & $\begin{array}{l}\text { Beginning designers propose and sketch ideas that superficially resemble viable solutions but do not support } \\
\text { deep inquiry into how (and if) a solution might function or behave. Informed designers use multiple } \\
\text { representations (gestures, words, text, simulations, prototypes) to explore and investigate design ideas in ways } \\
\text { that support deep inquiry into how a system works. }\end{array}$ \\
\hline $\begin{array}{l}\text { Pattern E. } \\
\text { Ignore vs. balance benefits and } \\
\text { trade-offs }\end{array}$ & $\begin{array}{l}\text { Beginning designers ignore or pay too little attention to design criteria and constraints, make design decisions } \\
\text { without weighing options and trade-offs, or attend only to pros of favored ideas and cons of lesser approaches. } \\
\text { Informed designers balance systems of benefits and trade-offs, using words and graphics, when they consider } \\
\text { plans or make and justify decisions. }\end{array}$ \\
\hline $\begin{array}{l}\text { Confounded vs. valid tests and } \\
\text { experiments }\end{array}$ & $\begin{array}{l}\text { Beginning designers run few tests on their design prototypes, and when they run tests, they can confound } \\
\text { experiments that cannot provide useful information about potential solutions and their performance. } \\
\text { Informed designers conduct valid tests as part of their investigations that help them learn quickly about key } \\
\text { variables, materials, users, and ways to optimize performance of prototypes. }\end{array}$ \\
\hline $\begin{array}{l}\text { Unfocused vs. diagnostic } \\
\text { troubleshooting }\end{array}$ & $\begin{array}{l}\text { Beginning designers use unfocused, non-analytical ways to view prototypes during testing and troubleshooting ideas. } \\
\text { Informed designers focus their attention on problematic areas and subsystems when troubleshooting devices and } \\
\text { proposing ways to fix them. }\end{array}$ \\
\hline $\begin{array}{l}\text { Haphazard or linear vs. managed and } \\
\text { iterative designing }\end{array}$ & $\begin{array}{l}\text { Beginning designers design in haphazard ways, working at random on whatever problems emerge or they } \\
\text { treat design as a set of strategies to be done once in linear order. Informed designers design as an iterative } \\
\text { process, improving ideas and prototypes based on feedback and cycling back to upgrade their understanding } \\
\text { of the problem, managing time and resources strategically, and using design strategies multiple times as } \\
\text { needed, in any order. }\end{array}$ \\
\hline Tacit vs. reflective design thinking & $\begin{array}{l}\text { Beginning designers do tacit designing when they think and act with little self-reflection and do little } \\
\text { monitoring of their own or others' actions either in the moment or after the work is done. Informed } \\
\text { designers practice reflective thinking in a metacognitive way by reviewing and keeping tabs on design } \\
\text { strategies and thinking while working and after work is finished. }\end{array}$ \\
\hline
\end{tabular}


notes included scientific explanations and provided information on students' actions and the reasoning associated with these actions.

For this exploratory study, we were purposeful in our selection of the cases. We wanted to select students from the same section to account for a similar course experience. The subsample that met all selection criteria ultimately included two senior high school students with the richest reflective notes from a course, named capstone design. Such reflectivity suggests that these students were at a place more than average in the beginning-informed designer spectrum. Each student, given the pseudonyms of Andrew and Brent, generated two design solutions addressing a design challenge described in the following section.

\section{Design challenge}

The design problem, the solar urban design challenge (Xie et al. 2014b), asked students to design energyefficient, passive solar buildings on a blank square city block surrounded by existing buildings of different heights (see Figure 2).

The design challenge, described in Figure 3, involves the use of design practices to consider solar radiation as it varies over a day and over seasons, analyze simulation data, consider constraints, make trade-offs, and optimize solutions (e.g., minimize the energy required to heat a building in the winter and minimize the energy required to cool a building in the summer). The Energy3D environment allows verification or testing of design performance within the software (Xie et al. 2014a).

Students used a computer-aided design (CAD) software, Energy3D, to design solutions for the built environment based on solar energy and heat transfer concepts (i.e., science knowledge) addressing the following engineering principles (i.e., design knowledge) outlined in the NGSS (Achieve 2013).

- HS-PS3-3. Design, build, and refine a device that works within given constraints to convert one form of energy into another form of energy.

- HS-ETS1-1. Analyze a major global challenge to specify qualitative and quantitative criteria and constraints for solutions that account for societal needs and wants.

- HS-ETS1-3. Evaluate a solution to a complex realworld problem based on prioritized criteria and trade-offs that account for a range of constraints, including cost, safety, reliability, and esthetics as well as possible social, cultural, and environmental impacts.

- HS-ETS1-4. Use a computer simulation to model the impact of proposed solutions to a complex real-world problem with numerous criteria and constraints on interactions within and between systems relevant to the problem.

\section{Data sources}

\section{Design replays}

The Energy3D software collected logs of student design actions in the background as students were sketching buildings, conducting experiments, collecting data using simulations, and taking reflective notes. These learner data were used to reconstruct the entire design process with all important actions restored for analysis. The snapshots (computer models, not images) were played back just like running a slide show. Student notes (text

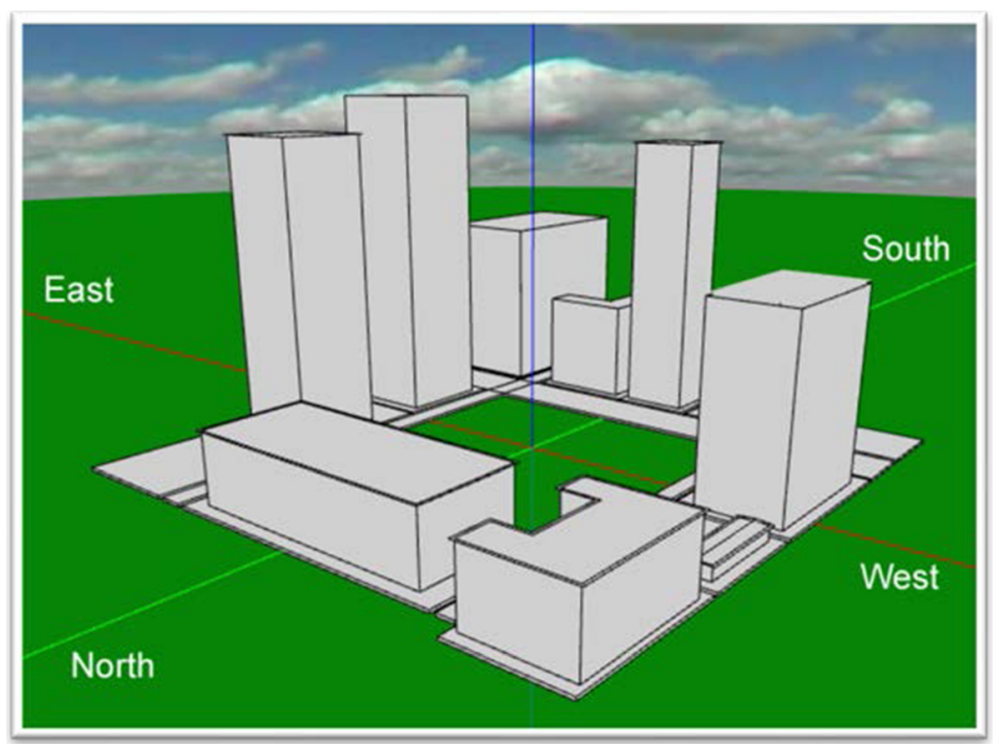

Figure 2 Solar urban design challenge. 


\section{City Block Design Challenge - Goals and Constraints}

Build at least two high-rise buildings: These are for residence and offices. No new construction, however, is allowed to be taller than the highest existing buildings in the neighborhood.

Build at least two low-rise buildings: These are for shops or services such as restaurants, book stores, or pharmacies. They should not be taller than 20 meters.

Build with a balance of built and open space: Approximately $1 / 3$ of the block must be constructed with high-rises and $1 / 3$ with low-rises. The remaining $1 / 3$ must be open space. The proportions do not need to be exact, however.

Build at most eight new buildings (including high- and low-rises): in total are allowed in the block.

Don't add windows: We assume that windows will be added proportionally to the total surface areas of each building later.

Parking areas, subway, or bus stations need not be considered.

Optimize solar gains of the high-rise buildings in the winter and summer: The locations and shapes of the high-rise buildings should be chosen such that they receive as much total solar energy on December $31^{\text {st }}$ as possible to lower the heating costs in the winter $A N D$ as little total solar energy on June $30^{\text {th }}$ as possible to lower the cooling costs in the summer.

No need to consider the solar gains of the low-rise buildings: They do not need a lot of sunlight because they accommodate business facilities that usually do not have many windows.

Figure 3 City block design challenge.

strings) to explain or reflect on their designs were replayed synchronously to their design actions such that we can coordinate the analyses of what they did and what they thought.

The computer recorded every action of the students. The datasets collected were large in that each design challenge required 5 to $7 \mathrm{~h}$ of classroom time to complete and summed up to approximately 20 megabytes at the end of a design project for a single active student. The replay of students' design actions can be sped up to provide a compressed view of the full design process, similar to time-lapse photography. In addition, these design replays can be stopped and restarted with one keystroke to better analyze each design action when needed.

Figure 4 presents the simulation of solar path (also called virtual heliodon), which students use to view the path of the sun. Another simulation allows viewing of the daily radiation heat map on all building surfaces. These features are helpful in understanding shadows related to both heating and cooling and enable students to visualize warmer and cooler parts of the building in multiple seasons. Figure 4 shows system capabilities in assisting students in balancing benefits and trade-offs from both a heating and cooling perspective as well as taking different seasons into account.

\section{Electronic notes}

The Energy3D system includes a note tool that allows students to enter electronic notes while designing. During the classroom implementation, students were encouraged to note their design process, decisions, and thinking and were instructed to take notes 'like an engineer' such as reasons for creating or selecting design features, describing tests to conduct about the performance of the current design, documenting performance and interpreting test results, and making plans for next steps. The student design rationales, collected through electronic notes within the system, were used in conjunction with the process data to gain a much clearer picture of student actions, learning, and reflection. 


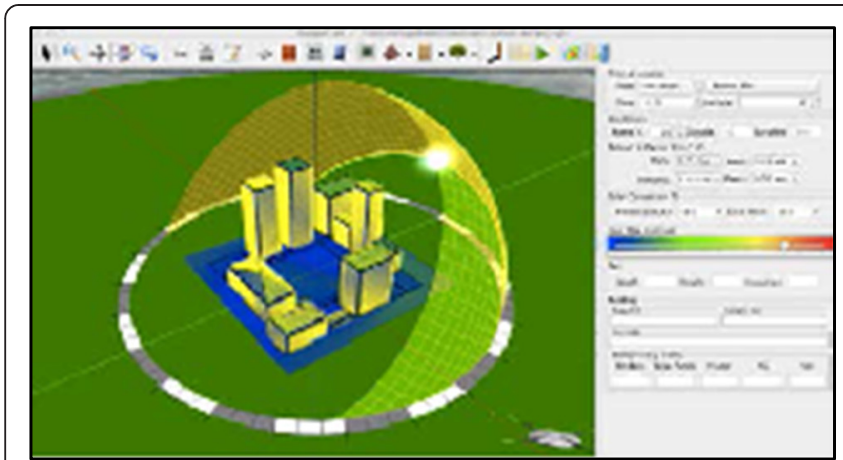

(a)

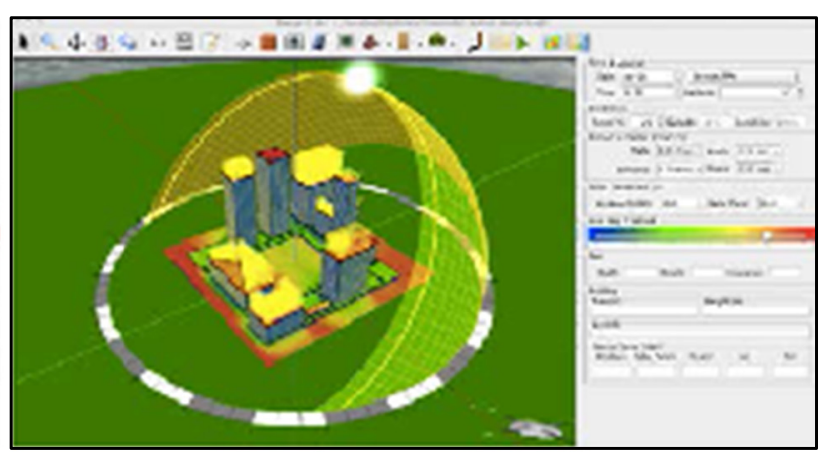

(b)

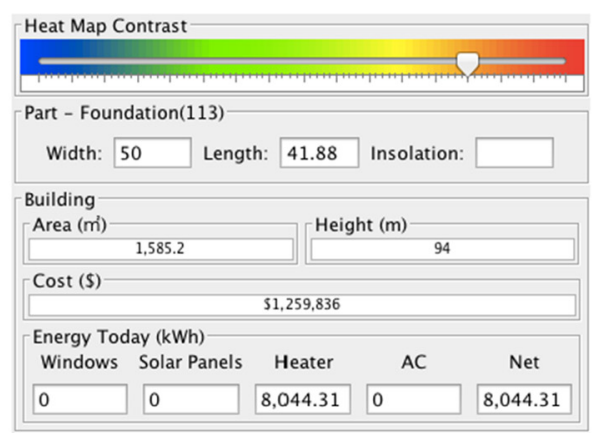

(c)

Figure 4 Energy3D simulations (a) analysis for December (b) analysis for July (c) detailed view of the quantitative analysis for December.

\section{Data analysis}

Because we were interested in the interaction between science inquiry and design, which was defined as making and explaining knowledge-based decisions in Figure 1, design decisions were our unit of analysis. To characterize observable patterns of student design behaviors within the video playbacks and student notes, we developed and used the informed design coding protocol based on the Informed Design Learning and Teaching Matrix (Crismond and Adams 2012). Finally, we used Valkenburg's (1998) representational system to visually display students' decision-making over time in terms of observable student design patterns. This also provided a mechanism for connecting macro-level iterations that addressed system-wide performance to micro-level iterations that addressed local issues.

\section{Development of the informed design coding protocol}

Each set of design decisions (moves), with student notes as further evidence when available, was mapped against the Informed Design Learning and Teaching Matrix (Crismond and Adams 2012). Table 2 includes examples of these behaviors as exhibited by Andrew and Brent. We did not consider pattern d, deep drawing, and modeling, from the Informed Design Learning and Teaching Matrix, due to the fact that the given project uses a
CAD system without the explicit use of other forms of representations.

Each student's design replays were reviewed in 10-s increments, which corresponded to 6 to $7 \mathrm{~min}$ of the actual class time, similar to time-lapse photography. Prior studies show data from such low-fidelity approaches are compatible with high-fidelity approaches where the observer is physically co-located with the student observed (Baker et al. 2006; Zhang et al. 2014). In addition, this approach allowed researchers to see subtle actions that are not obvious to the human eye. While designing, students typically made CAD design moves at a pace that allows these steps to be accelerated for analysis.

Within each 10-s increment, student design actions (moves) were reviewed and coded using the action categorization scheme presented in Figure 5. This categorization was used in combination with student notes to understand design episodes when the student was working within one goal or frame of the problem (see Figure 6). For example, within a frame, a student may write notes in which he reflects upon or considers the actions he has been taking in relation to a goal such as revising the roof while reflecting about increasing shade and decreasing the energy profile in the summer. Next, these chunks of time with similar goals served as input for characterization and visualization 
of the intersection of scientific explanation and design processes. Together, these actions formed a coherent design episode.

Valkenburg's (1998) representational system was then used to visually display students' decision-making over time in terms of observable student design patterns. This also provided a mechanism for connecting macro-level iterations. Figure 5 shows the symbols that were used to create visual representations of the design episodes based on the informed design coding protocol. Each design episode started with a goal, represented with an oval. The triangles are representative of moves or student actions such as making, editing, or changing roof shape. When a connection to a science concept is made, this was indicated with a blue dot. Student reflections are shown with a diamond.

\section{Results and discussion}

The analysis of Andrew's and Brent's design notes and design actions, resulted in a series of coherent activities reflecting informed design behaviors. Brent's full design process is used for this illustrative example to show how he made connections to science concepts. Andrew exhibited similar patterns in his design process as well. In Figure 6, all design episodes for Brent are represented in sequential order, composed of six episodes. All seven patterns of informed design behaviors were evident in both Andrew and Brent's design processes: problem framing, doing background research, idea fluency, balancing benefits and trade-offs, diagnostic troubleshooting, managed and iterative designing, and reflective design thinking.

As illustrated in Figure 6, the use of science concepts appeared in four episodes (episodes 1, 2, 3, and 5) along with trade-off analysis he engaged in. Where there was no trade-off analysis, there were no explicit connections to science. Reflective design thinking was also evident in these episodes. Episodes 4 and 6 were the only two instances where Brent did not make a science connection. These episodes also did not include any written reflections or evidence of an explicit trade-off analysis. During idea fluency, when Brent affluently generated and tested a large number of ideas, there was no evidence of reflective thinking and consequently no scientific explanations.

Throughout his design process, Brent made connections to two science concepts: heat transfer and seasonal solar path. As illustrated in Episode 1 in Figure 6, he conducted experiments that resulted in scientific explanations on the relationship between building geometry (more specifically surface area) and the solar energy gains. In

Table 2 Informed design coding protocol

\begin{tabular}{ll}
\hline Informed design patterns & Data description \\
\hline Problem framing (understand the challenge) & $\begin{array}{l}\text { Student spent time reviewing the criteria and constraints and specifically } \\
\text { mentioned these elements in the student notes }\end{array}$ \\
Doing background research (build knowledge) & $\begin{array}{l}\text { Student tested design features early in the episode (i.e., designed a basic } \\
\text { building to get a sense of its baseline performance) } \\
\text { Idea fluency (generate ideas) }\end{array}$ \\
$\begin{array}{l}\text { Student worked with a large variety of ideas (i.e., building height, width, roof } \\
\text { characteristics, or location). Student was able to work with one idea element at } \\
\text { a time (i.e., building height) or several elements at a time. }\end{array}$
\end{tabular}

Balance benefits and trade-offs through experimentation (weigh options and make decisions through conducting experiments)

Diagnostic troubleshooting (troubleshoot)

Managed and iterative designing (revise/iterate)

Reflective design thinking (reflect on process)
Student made design moves (adjust building height, width, roof characteristics, location) and performed the solar path analysis to determine the performance associated with the move. Sometimes notes regarding the experimental nature of the move were explicit. Student ran the solar analysis in two different seasons, weighing design options based on performance in summer and winter and making a decision. Student might change these building characteristics based on the analysis or might explicitly mention the positives and negatives about their design within a particular season.

Student made a move to resolve a specific perceived issue in the design (e.g., 'In the summer the building's roof puts a shadow almost all the way to the bottom of the building making the sunlight on that area be very cold (dark blue color) while the other sides such as the back and etc. still received a substantial amount of heat...')

Student started with a good working solution but explored ways to make it better. This differs from fluency; in that, this is a micro-level improvement on a solution. Small revision or 'tweak' to one characteristic of a design that usually occurs later in an episode. Could be accompanied by reflection if other elements of the Informed Design Matrix are involved.

Student made electronic notes in the system that are more than recordkeeping of values but show consideration for how their design efforts affect performance 


\begin{tabular}{|c|c|c|c|c|}
\hline Framework & Description & Source of evidence & \multicolumn{2}{|c|}{$\begin{array}{l}\text { 'Symbol' in } \\
\text { representation } \\
\text { system }\end{array}$} \\
\hline Design goal & $\begin{array}{l}\text { The goal of a sequence of activities or the } \\
\text { frame of actions }\end{array}$ & Student notes & & \\
\hline Design moves & $\begin{array}{l}\text { The activities students can do within the } \\
\text { system (e.g., make, edit, delete, change } \\
\text { shape, change orientation, simulation, } \\
\text { etc.) }\end{array}$ & \multicolumn{2}{|l|}{$\begin{array}{l}\text { Design replays from log } \\
\text { file }\end{array}$} & \\
\hline Self-reflection & $\begin{array}{l}\text { Reflection or thinking about the actions in } \\
\text { relation to the goal or frame }\end{array}$ & \multicolumn{2}{|c|}{$\begin{array}{l}\text { Student notes - explanations } \\
\text { that link goals to actions }\end{array}$} & \\
\hline $\begin{array}{l}\text { Science } \\
\text { concept }\end{array}$ & $\begin{array}{l}\text { Denotes existence of or reference to a } \\
\text { science concept }\end{array}$ & \multicolumn{2}{|c|}{ Student notes - explanations } & - \\
\hline
\end{tabular}

Figure 5 Action visualization protocol.

episodes 1 and 2, he recognized that the larger the surface area the greater the heat gain was. He also associated surface area with specific geometric shapes. For example, he justified building a parabola-shaped building (i.e., a U-shaped building) to increase the amount of solar heat energy transferred to the building. As his reflective notes in episodes 3 and 4 show, Brent made explicit efforts to establish a trade-off between heating in winter and cooling in summer.

Hence, it appears that exhibiting design behaviors of balancing benefits and trade-offs through experimentation was more conducive to students making connections to science concept during engineering design. According to Jonassen (2012), the trade-off analysis is a rational model of decision-making and an avenue for metacognitive awareness that opens opportunities for learning (Jonassen 2012). In our study, we similarly found evidence of systematic experimenting, scientific explanations, and decision-making at times when trade-off was to be made. Moreover, in authentic engineering design practice, reasoning through benefits and trade-offs of different design alternatives is an important component of decision-making (National Research Council 2012). In balancing benefits and trade-offs, students practice weighing options from experimentation and making decisions rather than focusing solely on the features of their design solutions.

The actions associated with trade-off analysis did not occur in a continual form. In fact, there was evidence of macro iterations in Brent's full design processes starting from episode 1 leading to episode 6 . These macro iterations occurred between idea fluency and trade-off analysis and exposed managed and iterative designing. In episodes 1, 2, and 3, Brent's focus was on trade-off analysis with some evidence of knowledge building, he engaged in idea fluency in episode 4 . In episode 5 , he went back to trade-off analysis and then moved back to idea fluency in episode 6. In the informed design coding protocol, idea fluency represents the student working with a large variety of ideas (i.e., building height, width, roof characteristics, or location) with the ability to work with one idea element at a time (i.e., building height) or several elements at a time. Idea fluency represents exploration of design alternatives in greater breadth and/or depth. In the exploratory cases of Andrew and Brent, there were no explicit evidence for science connections during idea generation and testing; however, macro iterations were evident between generating multiple designs through idea fluency and balancing benefits and trade-offs. It is possible that idea fluency allowed students to apply their new understandings into designs or gain information about their designs that are later tested more systematically through trade-off analysis. The visualization of the design episodes of Brent allowed us to better understand students' design goals through their design processes and reflective notes.

This exploratory study concludes that students explicitly explore and develop scientific explanations when balancing design benefits and trade-offs. Such decision-making through trade-off leads to opportunities for meaningful science learning. There are two critical variables that are likely to influence this phenomenon. First, learning becomes apparent through reflective design and reflective notes that illustrate the negotiation of benefits and trade-offs. Hence, without the reflective thought process or structures that reinforce the expressing of such thinking, learning may not be possible. 


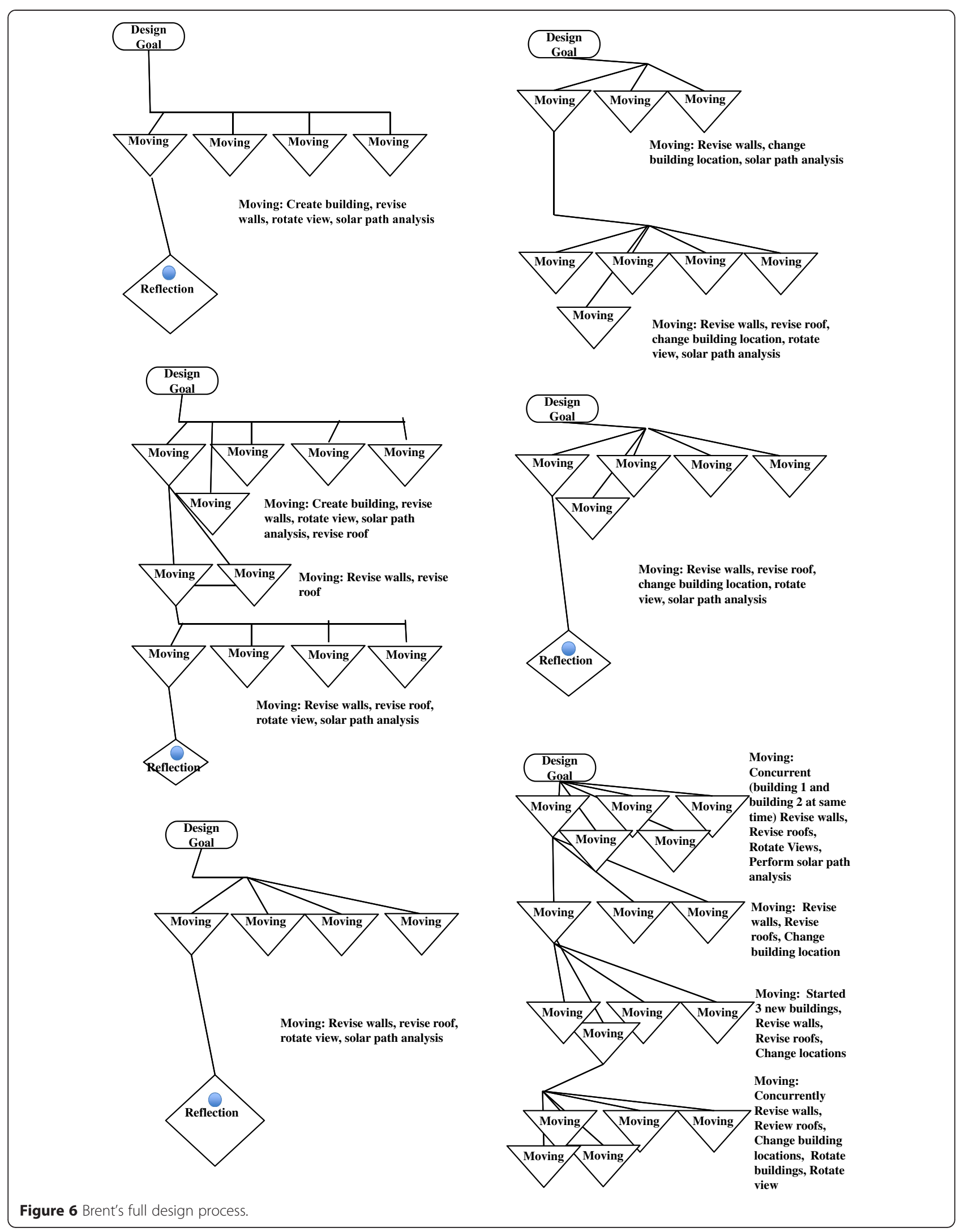


Second, people in general, not just students, struggle with evaluating trade-offs (Scholten and Sherman 2006), demonstrating that such decision-making is not necessarily a naturally easy process (Papadouris 2012). Without well-constructed design problems, most students cannot consider or fully engage with the complexity of weighing trade-offs in making design decisions.

\section{Conclusions}

As noted in the introduction, while engineering design has been considered to be a component of $\mathrm{K}-12$ education curricula and standards for decades, there is little research on how the students learn to apply science through design. In this study, we attempted to untangle and deconstruct two high school students' engineering practices as intertwined activities between engineering design and scientific explanations. Analyzing design behaviors as a series of design episodes provided ways to visualize student design processes, which was facilitated by the Energy3D system. Student design replays and reflective notes provided evidence that characterized engineering and scientific practices. As a result, we present a framework for explaining this intersection and an emergent theory of engineering-science integration.

This exploratory study included two highly reflective high school students who were able to engage in divergent and convergent behaviors. Future research should explore patterns for a more diverse group of students and ways to visualize these patterns with large samples of students. In conclusion, the results suggest that for science learning to occur, design projects used in classrooms should allow and emphasize trade-off analysis and include time and resources for supporting trade-off decisions through experimenting, data gathering, and reflection. Abilities to conduct trade-off analysis should be a desired learning objective in its own right and should be appropriately scaffolded for students.

\section{Competing interests}

The authors declare that they have no competing interests.

\section{Authors' contributions}

SP, MG and RA co-designed the informed design coding protocol, outlined data analysis procedures, and finalized the manuscript. MG carried out the data analysis and drafted the manuscript. CX and SN are the lead software developers of Energy3D, developed the solar urban design challenge model, and collected all data. All authors read and approved the final manuscript.

\section{Acknowledgements}

This work presented in this manuscript is based upon work supported by the National Science Foundation under Grant DUE \#1348547 and DUE \#1348530. Any opinions, findings, and conclusions or recommendations expressed in this paper, however, are those of the authors and do not necessarily reflect the views of the NSF. We thank Anthony larrapino, William Jumper, and Roger Morneau of Lowell High School, Massachusetts, for pilot-testing our software and materials in their classes.

\section{Disclaimer}

We, the authors, feel obliged to clarify that inquiry is not limited to natural sciences but serves many other disciplines such as history. Design as a set of strategies is itself an inquiry and serves a number of disciplines such as architecture, choreography, education, and engineering. However, these two terms (design and inquiry) have specific meanings in K-12 STEM education. Hence, in this manuscript when we use the term inquiry, we are referring to scientific inquiry and when we use the term design we are referring to design inquiry.

\section{Author details}

${ }^{1}$ School of Engineering Education, Purdue University, Wang Hall 4545, 516 Northwestern Avenue, West Lafayette, IN 47906, USA. ² School of Engineering Education, Purdue University, Armstrong Hall, 701 West Stadium Avenue, West Lafayette, IN 47906, USA. ${ }^{3}$ The Intelligent Learning Environments Laboratory, The Concord Consortium, 25 Love Lane, Concord, MA 01742, USA.

Received: 20 September 2014 Accepted: 11 February 2015 Published online: 20 May 2015

\section{References}

Adams, RS, Turns, J, \& Atman, CJ. (2003). Educating effective engineering designers: the role of reflective practice. Design Studies, 24(3), 275-294.

Apedoe, XS, Reynolds, B, Ellefson, MR, \& Schunn, CD. (2008). Bringing engineering design into high school science classrooms: the heating/cooling unit. Journal of Science Education and Technology, 17(5), 454-465.

Apedoe, XS, \& Schunn, CD. (2013). Strategies for success: uncovering what makes students successful in design and learning. Instructional Science, 41(4), 773-791.

Ball, LJ, \& Christensen, BT. (2009). Analogical reasoning and mental simulation in design: two strategies linked to uncertainty resolution. Design Studies, 30(2), 169-186

Baker, RS, Corbett, AT, \& Wagner, AZ. (2006). Human classification of low-fidelity replays of student actions. In Proceedings of the Educational Data Mining Workshop at the 8th International Conference on Intelligent Tutoring Systems.

Brophy, S, Klein, S, Portsmore, M, \& Rogers, C. (2008). Advancing engineering education in P-12 classrooms. Journal of Engineering Education, 97(3), 369-387.

Bruner, JS. (1961). The act of discovery. Harvard Educational Review, 31, 21-32.

Bucciarelli, LL. (1996). Designing engineers. Cambridge: MIT Press. Chapter 1-2, 6.

Burghardt, MD, \& Hacker, M. (2004). Informed design: a contemporary approach to design pedagogy as the core process in technology. The Technology Teacher, 64(1), 6-8.

Cajas, F. (2001). The science/technology interaction: implications for science literacy. Journal of Research in Science Teaching, 38(7), 715-729.

Crismond, DP, \& Adams, RS. (2012). The informed design teaching and learning matrix. Journal of Engineering Education, 101(4), 738-797.

Cross, N. (2001). Design cognition: results from protocol and other empirical studies of design activity. In CM Eastman, WM McCracken, \& W Newstetter (Eds.), Design Learning and Knowing: Cognition in Design Education. New York: Elsevier Press.

Cross, N. (2006). Designerly ways of knowing. London: Springer. Chapter 1-2.

Daugherty, J, \& Mentzer, N. (2008). Analogical reasoning in the engineering design process and technology education applications. Journal of Technology Education, 19(2), 7-21.

Doppelt, Y, Mehalik, MM, Schunn, CD, Silk, E, \& Krysinski, D. (2008). Engagement and achievements: a case study of design-based learning in a science context. Journal of Technology Education, 19(2), 22-39.

Dorst, K. (2011). The core of 'design thinking' and its application. Design Studies, 32(6), 521-532.

Dubberly, H. (2004). How do you design? A compendium of models. Dubberly Design Office, San Francisco CA. [-Retrieved from http://www.dubberly.com/ wp-content/uploads/2008/06/ddo_designprocess.pdf]

Fish, J, \& Scrivener, SA. (1990). Amplifying the mind's eye: sketching and visual cognition. Leonardo, 23(1), 117-126.

Goel, V, \& Pirolli, P. (1992). The Structure of design problem spaces. Cognitive Science, 16(3), 395-429.

Goldschmidt, G. (1991). The dialectics of sketching. Creativity Research Journal, $4(2), 123-143$.

Goldschmidt, G, \& Smolkov, M. (2006). Variances in the impact of visual stimuli on design problem solving performance. Design Studies, 27(5), 549-569. 
Hmelo, CE, Holton, DL, \& Kolodner, JL. (2000). Designing to learn about complex systems. The Journal of the Learning Sciences, 9(3), 247-298.

Jonassen, DH. (2000). Toward a design theory of problem solving. Educational Technology Research and Development, 48(4), 63-85.

Jonassen, DH. (2012). Designing for decision making. Educational Technology Research and Development, 60(2), 341-359.

Kolko, J. (2010). Abductive thinking and sensemaking: the drivers of design synthesis. Design Issues, 26(1), 5-28.

Kolodner, JL. (2002). Facilitating the learning of design practices: lessons from an inquiry into science education. Journal of Industrial Teacher Education, 39(3), 9-40.

Kolodner, JL, Crismond, D, Fasse, BB, Gray, JT, Holbrook, J, Ryan, M, et al. (2003). Problem-based learning meets case-based reasoning in the middle-school science classroom: putting a learning-by-design curriculum into practice. Journal of the Learning Sciences, 12(4), 495-548.

Lachapelle, CP, \& Cunningham, CM. (2014). Engineering in elementary schools. In S Purzer, J Strobel, \& ME Cardella (Eds.), Engineering in pre-college settings: synthesizing research, policy, and practices. West Lafayette, IN: Purdue University Press.

Lawson, B, \& Dorst, K. (2009). Design expertise. Oxford, UK: Architectural Press (Elsevier).

Lewis, T. (2006). Design and inquiry: bases for an accommodation between science and technology education in the curriculum? Journal of Research in Science Teaching, 43(3), 255-281.

National Academy of Engineering and National Research Council. (2014). STEM integration in K-12 education: status, prospects, and an agenda for research. Washington, DC: The National Academies Press.

National Research Council. (1996). National science education standards. Washington, DC: National Academies Press.

National Research Council. (2009). Engineering in K-12 education: understanding the status and improving the prospects. Washington, DC: National Academies Press.

National Research Council. (2012). A framework for K-12 science education: practices, crosscutting concepts, and core ideas. Washington, DC: National Academies Press.

Achieve. (2013). Next generation science standards: for states, by states. Washington, DC: National Academies Press.

Paletz, S, Schunn, CD, \& Kim, KH. (2013). The interplay of conflict and analogy in multidisciplinary teams. Cognition, 126(1), 1-19.

Papadouris, N. (2012). Optimization as a reasoning strategy for dealing with socioscientific decision-making situations. Science Education, 96(4), 600-630.

Penner, DE, Giles, ND, Lehrer, R, \& Schauble, L. (1997). Building functional models: designing an elbow. Journal of Research in Science Teaching, 34(2), 125-143.

Purzer, Ş, Strobel, J, \& Cardella, ME. (2014). Engineering in pre-college settings: synthesizing research, policy, and practices. West Lafayette, IN: Purdue University Press.

Sadler, PM, Coyle, HP, \& Schwartz, M. (2000). Engineering competitions in the middle school classroom: key elements in developing effective design challenges. The Journal of the Learning Sciences, 9(3), 299-327.

Scholten, M, \& Sherman, SJ. (2006). Tradeoffs and theory: the double-mediation model. Journal of Experimental Psychology, 135, 237-261 and 552.

Schön, DA. (1993). The reflective practitioner: How professionals think in action. New York: Basic Books.

Schnittka, C, \& Bell, R. (2011). Engineering design and conceptual change in science: addressing thermal energy and heat transfer in eighth grade. International Journal of Science Education, 33(13), 1861-1887.

Schunn, CD, Silk, EM, \& Apedoe, XS. (2012). Engineering in and for science education. In J Shrager \& S Carver (Eds.), The journey from child to scientist: Integrating cognitive development and the education sciences (pp. 207-225). Washington, DC: American Psychological Association.

Snetsinger, C, Brewer, C, \& Brown, F. (1999). Capture the wind: students get a charge from wind energy. The Science Teacher, 66, 38-42.

Subramanian, K. (1999). Practical physics. The Science Teacher, 66, 37-39.

Svihla, V, \& Petrosino, AJ. (2008). Improving our understanding of K-12 engineering education. Paper presented at the International Conference on Engineering Education. Greece: Heraklion.

Valkenburg's, R. (1998). The reflective practice of design teams. Design Studies, 19(3), 249-271.

Vattam, SS, \& Kolodner, JL. (2008). On foundations of technological support for addressing challenges facing design-based science learning. Pragmatics \& Cognition, 16(2), 406-437.

Xie, C, Zhang, H, Nourian, S, Pallant, A, \& Bailey, S. (2014a). A study of the instructional sensitivity of CAD logs based on time series analysis. International Journal of Engineering Education, 30(4), 760-778.
Xie, C, Zhang, H, Nourian, S, Pallant, A, \& Hazzard, E. (2014b). A time series analysis method for assessing engineering design processes using a CAD tool. International Journal of Engineering Education, 30(1), 218-230.

Zhang, Z, Xie, C, \& Nourian, S. (2014). Detecting iterative cycles of engineering design from student digital footprints in computer-aided design software. Poster presented at the 2014 International Conference of the Learning Sciences. Boulder CO: International Society of the Learning Sciences.

Zubrowski, B. (2002). Integrating science into design technology projects: using a standard model in the design process. Journal of Technology Education, 13(2), 47-65

\section{Submit your manuscript to a SpringerOpen ${ }^{\odot}$ journal and benefit from:}

- Convenient online submission

- Rigorous peer review

- Immediate publication on acceptance

- Open access: articles freely available online

- High visibility within the field

- Retaining the copyright to your article

Submit your next manuscript at $>$ springeropen.com 